University of Vermont

UVM ScholarWorks

College of Agriculture and Life Sciences Faculty

Publications

College of Agriculture and Life Sciences

$11-1-2018$

\title{
Ensuring Compliance From 35,000 Feet: Accountability and Trade- Offs in Aviation Safety Regulatory Networks
}

\author{
Russell W. Mills \\ Bowling Green State University \\ Christopher J. Koliba \\ University of Vermont \\ Dorit Rubinstein Reiss \\ UC Hastings College of the Law
}

Follow this and additional works at: https://scholarworks.uvm.edu/calsfac

Part of the Community Health Commons, Human Ecology Commons, Nature and Society Relations Commons, Place and Environment Commons, and the Sustainability Commons

\section{Recommended Citation}

Mills RW, Koliba CJ, Reiss DR. Ensuring compliance from 35,000 feet: Accountability and trade-offs in aviation safety regulatory networks. Administration \& Society. 2018 Nov;50(10):1478-507.

This Article is brought to you for free and open access by the College of Agriculture and Life Sciences at UVM ScholarWorks. It has been accepted for inclusion in College of Agriculture and Life Sciences Faculty Publications by an authorized administrator of UVM ScholarWorks. For more information, please contact scholarworks@uvm.edu. 


\title{
Ensuring Compliance From 35,000 Feet: Accountability and Trade-Offs in Aviation Safety Regulatory Networks
}

Administration \& Society 2018, Vol. 50(10) 1478-1507

(C) The Author(s) 2016

Article reuse guidelines: sagepub.com/journals-permissions DOI: $10.1177 / 0095399716656223$ journals.sagepub.com/home/aas

\section{Russell W. Mills', Christopher J. Koliba², and Dorit Rubinstein Reiss ${ }^{3}$}

\begin{abstract}
A puzzle that faces public administrators within regulatory networks is how to balance the need for public or democratic accountability with increasing demands from interest groups and elected officials to utilize the expertise of the private sector in developing process-oriented programs that ensure compliance. This article builds upon the network governance accountability framework developed by Koliba, Mills, and Zia to explore the dominant accountability frames and the accountability trade-offs that shape the process-oriented regulatory regime used by the Federal Aviation Administration (FAA) to oversee and regulate air carriers in the United States.
\end{abstract}

\section{Keywords}

governance networks, regulation, accountability, aviation

\footnotetext{
'Bowling Green State University, Bowling Green, OH, USA

${ }^{2}$ University of Vermont, Burlington, VT, USA

${ }^{3} \mathrm{UC}$ Hastings College of Law, San Francisco, CA, USA

Corresponding Author:

Russell W. Mills, Bowling Green State University, 124 Williams Hall, Bowling Green, $\mathrm{OH} 43403$, USA.

Email: millsrw@bgsu.edu
} 
As industry processes become increasingly complex, regulatory agencies, often faced with demands for austerity and reductions in traditional inspection activities, have relied more on incentives, self-monitoring, and other less prescriptive tools to ensure compliance with government regulations and industry best practices (Gilad, 2010; Gormley, 1986; Parker, 2002). The shift from government-centered to process-oriented regulatory regimes including self-disclosure and self-audit programs has led to a proliferation of actors from the public, private, and non-profit sectors involved in compliance, monitoring, and oversight functions previously reserved for government agencies. This proliferation of actors has drastically altered the "principal-agent" relationship between regulator and regulated firm to one that is increasingly transactional and built upon the sharing of information related to the internal operation of the firm within regulator networks (Carpenter \& Krause, 2015; Koliba, Meek, \& Zia, 2010). The shift from a traditional principal-agent to a transactional and networked regulatory regime has serious implications for accountability given the heterogeneous perspectives and motivations of actors involved in ensuring compliance. The challenge of ensuring accountability in a process-oriented regulatory regime is particularly difficult in complex industries such as aviation.

Over the past two decades, aviation safety regulation has undergone a fundamental shift from a government-centered approach focused on governmental inspections of aircraft and pilots to a process-oriented regime focused on information and data exchange between frontline operators, air carriers, and regulatory agencies. The Federal Aviation Administration (FAA) has developed several voluntary disclosure programs in partnership with air carriers and employee unions to compliment their traditional inspection activities by offering frontline employees the opportunity to disclose violations to the FAA or the air carrier for reduced enforcement action. The data collected through voluntary disclosures allows the FAA and the air carrier to identify safety hazards and trends while also targeting their inspection and audit programs. In addition, the FAA's voluntary disclosure programs provide valuable secondary information on the safety culture of an air carrier to the agency (Mills \& Reiss, 2013). While these programs have obvious benefits to both the FAA, air carriers and employee unions, an unexplored element of these programs is the degree to which they shift the accountability structures of both public and private entities responsible for ensuring aviation safety in the United States. The aviation industry provides an interesting case to examine accountability trade-offs in regulatory networks due to the unique goal congruence (i.e., safety) between regulators and industry, and the significant reputation risks presented by an aviation disaster to both air carriers and the industry as a whole. 
This article will investigate the dominant accountability structures in the FAA's process-oriented regulatory approach to aviation safety. Adopting the network accountability framework developed by Koliba, Mills, and Zia (2011), we assess the degree to which process-oriented regulatory regimes and the voluntary disclosure programs that are often used to foster information exchange between regulated entities and regulators shift traditional conceptions of accountability. Using a dataset of over a dozen interviews with aviation safety inspectors and air carrier safety officials along with participant observations of collaborative safety processes and secondary sources of data including Congressional hearings and inspector general reports, we describe and analyze the FAA's aviation safety regime including two of the voluntary disclosure programs used to foster information exchange: the Aviation Safety Action Program (ASAP) and the Voluntary Disclosure Reporting Program (VDRP). We also develop a case study of an incident in 2010 involving Southwest Airlines (SWA) that illustrates the challenges of ensuring accountability in process-oriented regimes. The case studies are used to analyze the degree to which voluntary disclosure programs rely on complimentary accountability mechanisms that have traditionally been conceptualized as dichotomous or opposed (e.g., democratic and market-based accountability mechanisms).

We argue that to have effective process-based regulation, regulators and elected officials must design regimes that balance multiple accountability regimes to prevent actors from relying solely on their preferred accountability mechanisms. Put differently, if regulators rely only on the voluntary disclosure of incidents by firms without the threat of other accountability mechanisms such as fines or revoking of an operating certificate (i.e., good cop/bad cop enforcement strategies), then firms will often rely on the most familiar and arguably important accountability mechanism to them: shareholder accountability. In addition, we argue that balancing accountability regimes is easier to achieve for regulators when a third party, in our case, employee unions, is given authority to assist in the facilitation of processoriented regulatory programs. This suggests that a diversity of interests in the facilitation of process-oriented regulatory programs helps prevent actors from relying too heavily on one particular accountability mechanism. In our case, the presence of employee unions in one voluntary program helps prevent industry from engaging in large-scale regulatory deception while also helping prevent regulators from using self-disclosed data in punitive actions against employees and air carriers.

While the study presented here is based on two voluntary programs in one federal agency operating in a complex industry, we believe that its conclusions are generalizable to a number of other regulatory environments. First, 
while the alignment and strength of the incentives by all actors in the network to ensure safety is strong, several other regulatory arenas such as the regulation of HIV clinics, nuclear power plants, auto industry, and chemical plants have similar alignment of goals between regulators and industry (Heimer \& Gazley, 2012). Second, our analysis is very applicable to other high-reliability industries such as nuclear power, deepwater oil exploration, and chemical production where one regulatory failure can lead to significant reputation damage to not only the individual non-compliant firm but also the entire industry (Mills \& Koliba, 2015). Finally, the study here analyzes the dominant accountability regimes in aviation regulatory networks through routine and extreme cases. We feel this approach provides significant leverage to explore accountability within networks and is one that lends itself to replication across a variety of regulatory environments including food safety (Verbruggen, 2013), financial regulation (Larson, 2013), and oil exploration (Mills \& Koliba, 2015).

\section{Framing Network Accountability}

Accountability is "the obligation to give an account of one's actions to someone else, often balanced by a responsibility of that other to seek an account" (Scott, 2006, p. 175). Extensive literature addresses the complexity of accountability in modern states (Behn, 2001; Mashaw, 2006; May, 2007; Reiss, 2011; Scott, 2006). The most thorough treatment of accountability within regulatory governance networks was conducted by May (2007), who used an accountability framework developed by Romzek and Dubnick (1987) to show how political, legal, bureaucratic, and professional accountability structures vary across prescriptive, process-based, and performance-based regulatory regimes. In his examination of regulation in building and fire safety, food safety, and nuclear power plant safety, May (2007) found that a shift in prescriptive to process-based regulatory regimes has led to a substitution of professional accountability for bureaucratic accountability structures. While this finding is a significant contribution, it does not address the shift from a government-centered regulatory approach to one based more on process-oriented approaches that are contingent upon certain comfort levels among regulators, elected officials, and, to some degree, citizens for more market-driven and collaborative regulatory mechanisms. A framework that encompasses the role of markets and collaborative ties is needed. A more nuanced governance network accountability framework (Koliba et al., 2011) allows for a more in-depth analysis of the role that salience and complexity play in determining the dominant accountability structures within regulatory governance networks by juxtaposing market, democratic, and vertical and 
horizontal accountability structures. This broadened view of accountability allows for the comprehension of more heterogeneous mixture of complementary and competing factors.

The governance network accountability framework used here was first applied to the response and recovery efforts following the landfall of Hurricane Katrina to analyze intergovernmental relations in the response and recovery efforts (Koliba et al., 2011). Building from Romzek and Dubnick's (1987) seminal work, the authors expanded their accountability framework to include not only citizen, legal, bureaucratic, and professional accountability but also market-based accountability mechanisms along with collaborative accountability often found in governance networks. The authors identify three accountability frames: democratic, market, and administrative, and found that there was a tension between bureaucratic and collaborative accountability structures found within the administrative accountability frame, which led to confusion and a breakdown of administrative accountability between the Federal Emergency Management Agency (FEMA), the American Red Cross, and other volunteer organizations, as well as failures in democratic accountability of the intergovernmental network responsible for the preparation, response, and recovery efforts following the disaster. The governance network accountability model has been used to examine the accountability trade-offs challenging global attempts to develop international treaties to address climate change (Zia \& Koliba, 2011) and to identify the breakdowns in accountability that led to the Deepwater Horizon oil spill (Mills \& Koliba, 2015). In the latter, the authors apply the framework to a regulatory network and conclude that shareholder accountabilities (directed at profit maximization) usurped bureaucratic regulatory controls and professional standards, and led to the disaster. The FAA case presented here examines an industry that has had a much more robust legacy of process-oriented regulation, due in large part to the extreme emphasis placed upon safety not only by the regulator but also by industry. This robust legacy, that we argue is still vulnerable, is built on the establishment of a culture of cooperation and an authentic participatory decision-making model involving pilots and employee unions.

Table 1 outlines the application of the governance network accountability framework to regulatory governance networks at the federal level. The framework addresses the explicit standards and implicit norms that guide the relationship between those rendering account and those to whom accounts are rendered. Of particular interest is the market accountability frame, which is divided into three distinct, but interrelated, components: shareholder, consumer (Scott, 2006), and labor accountability. Shareholder accountability usually calls for the maximization of profit as the driving, explicit 


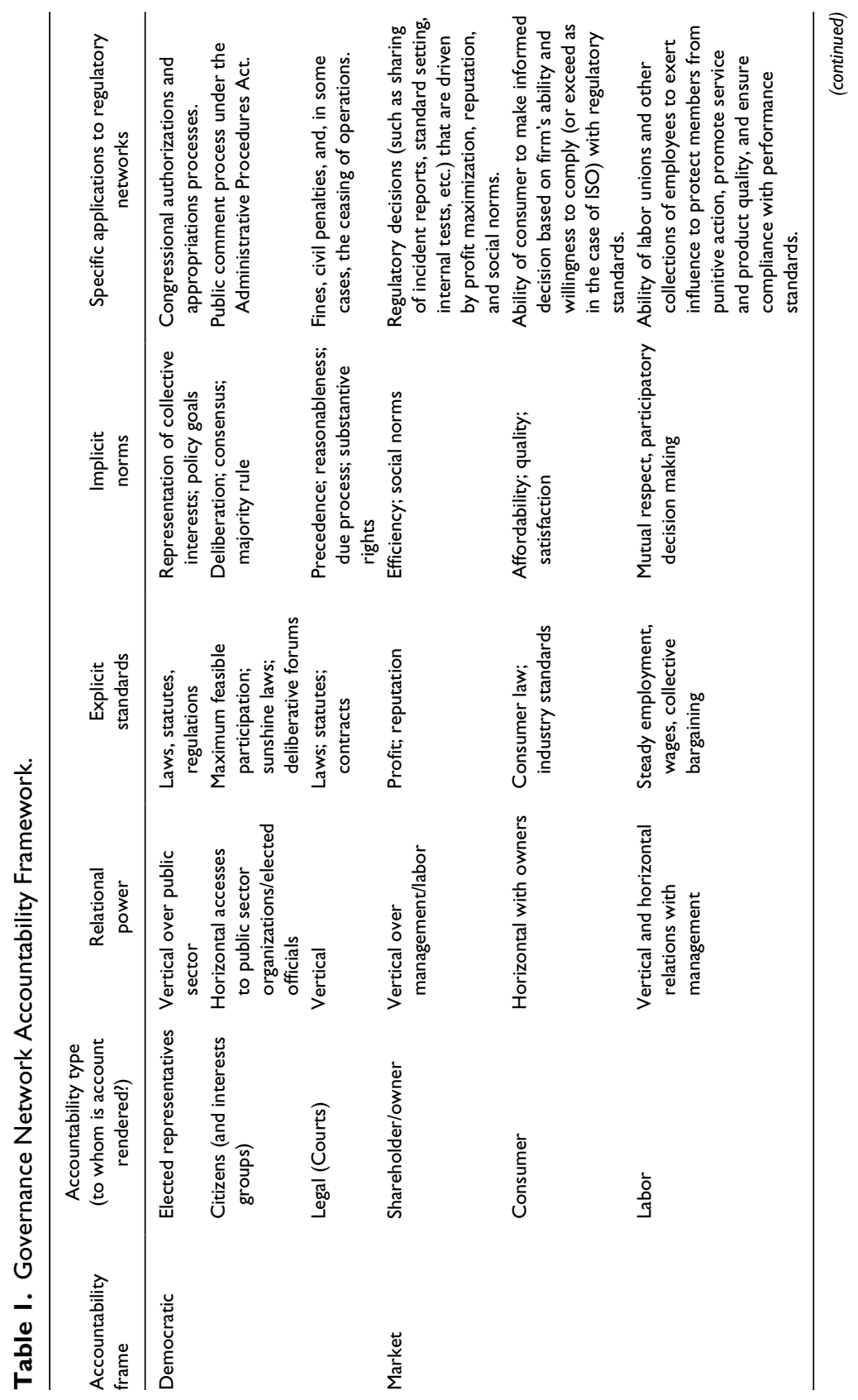




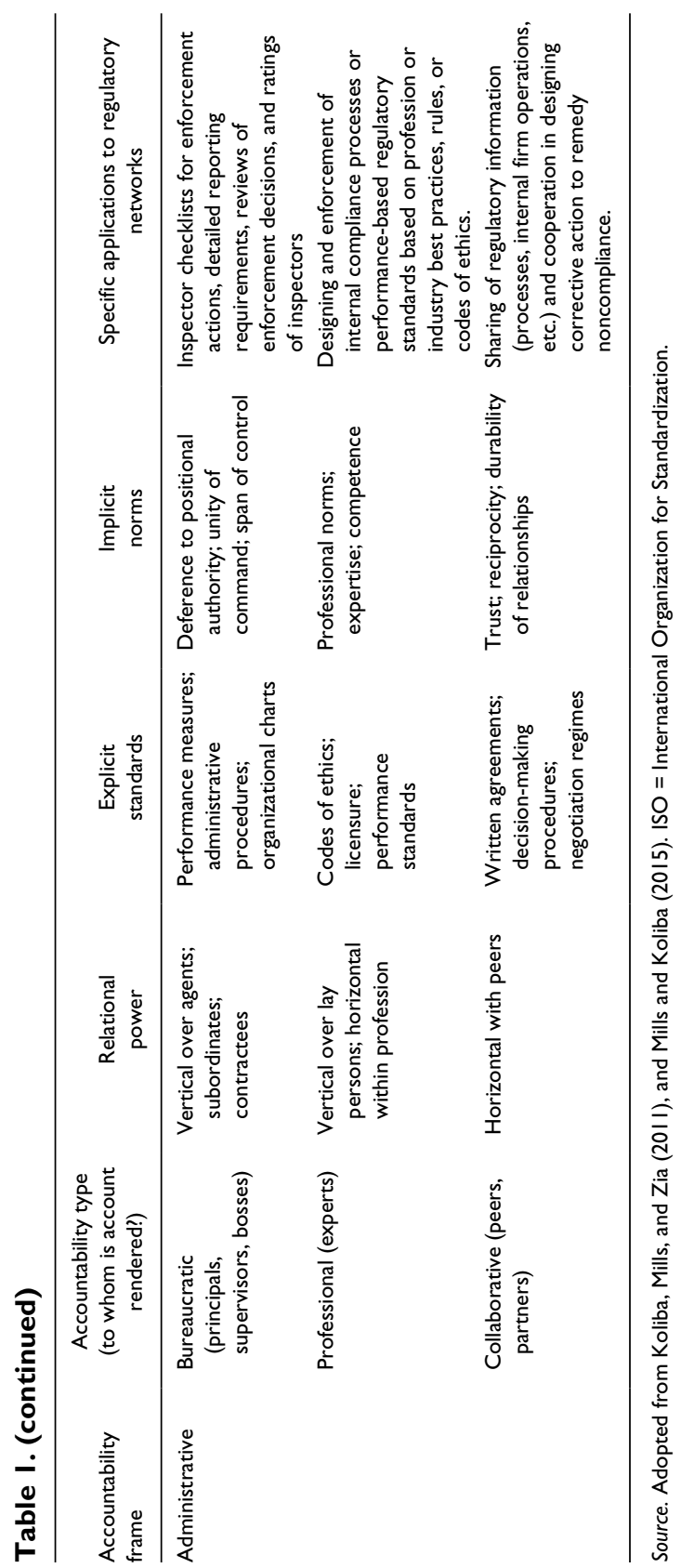


performance standard. As such, the services, products, and information of privately owned firms often are viewed as proprietary objects. Within regulatory governance networks, shareholder accountability takes the form of strategic decisions within firms of how, when, and what information to share with regulators. While the field of economics would predict that firms would look to design process-oriented or performance-based internal oversight or audit programs that minimize cost while providing an acceptable level of compliance, scholars have identified several instances where firms have gone "beyond compliance" standards established by regulators due to both societal pressures and a desire to maintain the organization's reputational capital (Ayres \& Braithwaite, 1992; May, 2005; Thornton, Gunningham, \& Kagan, 2005; Thornton, Kagan, \& Gunningham, 2009; van Erp, 2011). This body of literature suggests that shareholder accountability is more than a blind focus on profitability and stock price, but rather a multi-dimensional, nuanced, concept built not only on fear of fines for noncompliance but also the desire to maintain and enhance the firm's reputation for compliance.

Consumerist accountability is a market-based accountability predicated on the ability of consumers to choose between alternative, competing goods or services. Through a consumer's choice or refusal to purchase, the consumer may be understood as holding a corporation accountable. Within regulatory governance networks, consumer accountability is manifested through the ability of consumers to alter purchasing behaviors given a firm's capacity to meet regulatory compliance. Traditionally, the ability of consumers to examine the firm's capacity to meet regulatory compliance would be centered on incidents of noncompliance reported by regulators. However, scholars have examined cases, particularly in the area of environmental compliance, where firms will participate in voluntary programs that design and set industry standards that are above the minimum levels, such as the International Organization for Standardization (ISO) standards (Darnall, Potoski, \& Prakash, 2010; Prakash \& Potoski, 2006). By enacting these costly standards, firms can differentiate themselves either as good corporate citizens or safe operators in the eyes of their consumers. These government and industry centered voluntary programs provide more information to consumers to make an informed decision about the comparative level of compliance of firms in the marketplace.

Labor accountability encompasses the role that workers, be they formally organized into labor unions or not, play in market frameworks of accountability. Rosenbloom and Shafritz (1985) situate labor's role in providing accountability feedback as the cycling of information about the effect or results of the behavior of individual workers or whole labor systems back to those individuals or labor systems so that "human behavior or organizational 
performance might be modified—presumably improved" (p. 252). This kind of feedback generated from shareholders or managerial principals to agentlabor plays a role in ensuring job satisfaction and negotiated understandings of performance, rendered at both the individual and collective levels. This feedback can be directed in the other direction as well: Workers may provide feedback to an organization that may allow for the development of improved working conditions, refined modes of production and service delivery, and assurances of quality control. Developing such feedback loops was the basic premise of total quality management (TQM) efforts in the late 1980s and 1990s and continues to this day through development of participative decision-making models (PDM). Research into labor-management relationships sheds additional light on the value that these kind of mutually reinforcing feedback loops play. An optimal PDM relies on the existence of "viable collaborative mechanisms" that are "available and understood by management and employees," premised on an authentic desire to establish "win-win" expectations (and realizations) among all parties. PDM requires that a level of "trust and mutual respect must exist among the various parties" (Kearney $\&$ Hays, 1994, p. 47). When this trust and mutual respect exists, and mechanisms for communication and feedback flow between employees, shareholders, and management, labor accountability is built on the informal capacity of individual workers as well as workers organized into collective interests (e.g., unions) to hold others accountable.

Angle and Perry (1986) describe PDM as existing within a culture of "ambient conflict or cooperation." Within more cooperative climates, accountabilities to and from labor will be based on a level of trust. Cultures of conflict between labor, shareholders, and management have led to the establishment of organized labor unions.

A cooperative labor relations climate has been found to positively influence levels of organizational commitment and union loyalty, as well as productivity and quality of services (Deery \& Iverson, 2005, p. 600). When labor unions are present, the role of labor accountabilities is formalized around the rights to negotiate contracts, and enter into formal grievance processes and, in some cases, strike. These actions provide very explicit ways that organized labor can hold market-based organizations, as well as governments that have permitted civil servants to organize, accountable.

Thus, the role of labor as a contributor to market-based accountability frameworks is shaped by the persistence of conflictual and/or cooperative relations with shareholders and management. The FAA case presented here highlights the critical role that an ambient cooperative culture, combined with formal labor union roles, can play in ensuring that the airline industry is safe - an obvious performance standard that is now expected by consumers, 
elected officials, and citizens in general. Labor's role in ensuring that safety performance goals are attained is clearly highlighted in this case.

Table 1 provides an overview of the entire accountability framework, including the democratic and administrative frames in play in complex regulatory situations. A detailed description of this entire framework can be found in other publications cited in the table heading.

In this study, we explore the dominant accountability structures and the trade-offs between accountability frames through an examination of voluntary self-disclosure programs operated by the FAA. The FAA's voluntary disclosure programs provide an interesting and theoretically relevant case to examine accountability structures for a number of reasons. First, unlike many other industries, both the regulated entity (air carriers) and the regulator (FAA) have a strong incentive to ensure a high degree of safety regardless of cost. The alignment of motives and incentives in aviation safety is unique because following an aviation crash or incident, the perception of air travel as being "unsafe" can have serious financial implications not just for the air carrier involved in the incident but for the industry as a whole (Mills \& Reiss, 2013). In other words, consumers' fears can affect their decisions to fly, and to fly with specific carriers. Second, the collaborative nature of the FAA's voluntary self-disclosure programs provides an appropriate venue to examine accountability trade-offs that take place in transactional interactions between regulated firms and regulatory agencies. Third, compared with other parts of the world, the FAA's programs are much more mature and well developed. In Europe, for example, the EU only recently announced that it would direct its safety agency (the European Aviation Safety Agency, [EASA]) to establish voluntary reporting programs similar to those operated by the FAA. Finally, the FAA case provides an arena to examine accountability structures in both routine and challenging regulatory environments.

In this article, we use the FAA case to answer the following question: Given the shift to process-oriented regulation rooted in collaborative, transactional authority between regulators and regulated firms, what are the dominant accountability structures in the FAA's voluntary self-disclosure programs and what are the trade-offs between accountability frames that determine the effectiveness of the network of actors in ensuring safety?

\section{Method}

This article uses a single-embedded case study design (Yin, 2013) by focusing on two separate voluntary disclosure programs within the same agency (the FAA). This approach allows for an integrated analysis of the voluntary disclosure programs operated by the FAA along with the dominant 
Table 2. Data Used in FAA Case Study.

\begin{tabular}{lll}
\hline Interviewee/Observation & \multicolumn{1}{c}{ Organization } & \multicolumn{1}{c}{ Date } \\
\hline Voluntary Program Manager & FAA & November 6, 2009 \\
Voluntary Program Manager & FAA & February 22, 2010 \\
ASIAS Program Manager & FAA & February 24, 2010 \\
Inspector & FAA & February 18, 2010 \\
Principal Inspector & FAA & February 18, 2010 \\
Inspector & FAA & April 7, 2010 \\
Inspector & FAA & April 20, 2010 \\
Program Manager & NASA & April I, 2010 \\
ASAP Program Manager & Air Carrier & April 20, 2010 \\
ASAP Program Manager & Air Carrier & April 26, 2010 \\
Director of Safety Management & Air Carrier & May 14, 2010 \\
Systems (SMS) & & May 20, 2010 \\
Director of Regulatory & Air Carrier & \\
Compliance & Aviation Trade Association & June I, 2010 \\
General Council & Air Carrier, FAA, Labor & April 27, 2010 \\
Event Review Committee & Union & \\
Observation & Air Carrier, FAA, Labor & May 13, 2010 \\
Event Review Committee & Union & \\
Observation & & \\
\hline
\end{tabular}

Note. $\mathrm{FAA}=$ Federal Aviation Administration; ASIAS = Aviation Safety Information Analysis and Sharing; ASAP = Aviation Safety Action Program.

accountability frames in each program. Yin (2013) argues that single-case designs are appropriate for examining unique cases that can shed light on new social phenomena. The FAA represents a unique governmental agency through which to examine accountability in voluntary disclosure programs for several reasons including the historically close relationship with commercial aviation, the history of reform within the FAA due to external perturbations including aviation disasters, the number of actors responsible for ensuring aviation safety, the common goal of safety among regulators and industry (Mills \& Reiss, 2013), and the complex task environment in which the FAA operates (i.e., regulate air commerce, promote aviation, manage air traffic control, etc.).

The primary data used to develop the ASAP and VDRP case studies are a total of 13 interviews and two participant observations (Table 2). Specifically, the lead author interviewed three FAA headquarters staff responsible for designing and implementing both ASAP and VDRP at the national level, four FAA field managers/inspectors responsible for overseeing ASAP and VDRP 
implementation at four different air carriers, four air carrier managers (from four different air carriers) responsible for implementing ASAP and VDRP, one NASA official responsible for analyzing ASAP data at the national level, and one aviation trade association official who was responsible for creating VDRP and who has experience in implementing both programs. In addition, one of the authors was granted access to two confidential ASAP Event Review Committee (ERC) meetings with two separate air carriers. While the number of interviews and observations is fairly limited, the sample of air carriers and their corresponding local FAA offices that were selected by the authors provide a representative sample comprised of a variety of air carriers including two major legacy air carriers, one low-cost carrier, and one regional carrier. This diverse sample of air carriers and local FAA offices also comprised a variety of relationships between the local regulator and regulated entity, ranging from very collaborative to adversarial (see Mills, 2010), which provides additional theoretical leverage for assessing the dominant accountability frames that are present in both ASAP and VDRP. Individual interviewees were chosen through a purposive snowball sampling approach. Specifically, following meetings and interviews with FAA headquarters personnel familiar with all VDRP and ASAP programs in operation, the authors contacted a sample of FAA local officials and air carrier officials listed by the FAA headquarters staff for interviews based on the type of air carrier (major, regional, low cost) and the type of perceived interaction (collaborative or adversarial) between the local FAA office and the air carrier as identified by FAA headquarter personnel.

Secondary sources of data include scholarly and news accounts of the FAA's voluntary disclosure programs, documentation from Congressional hearings, and reports from the Government Accountability Office (GAO) and Department of Transportation Inspector General (DOT-IG). The secondary sources of data were used to develop a detailed account of the SWA incident that illustrated the difficulty of ensuring accountability in voluntary disclosure programs. The data collected via the interviews and observations were analyzed using an open coding scheme developed to gain insight into the behaviors by regulators and air carrier officials in each program. The researchers triangulated the coded interview data with several other sources of data including GAO and DOT-IG reports, news accounts, and the ERC observations to derive the in-depth examination and analysis of accountability within the FAA's voluntary self-disclosure programs and the SWA incident.

\section{Aviation Safety Regulation in the United States}

The FAA is the primary regulatory agency in charge of air transportation in the United States and is tasked with regulating both commercial and general 
aviation, promoting and encouraging the development of air service, developing and maintaining a system of air traffic control, and developing programs that mitigate the environmental effects of air transportation. A major task of the FAA is to issue and enforce safety regulations that set minimum standards covering manufacturing, operating, and maintaining aircraft. To enforce its laws, rules, and certificates, the FAA employs approximately 4,000 aviation safety inspectors who conduct periodic inspections of airmen, maintenance operations, and repair stations to ensure compliance. The FAA organizes its inspection activities through its Certificate Management Offices (CMOs), which is a team of operations (pilots) and maintenance inspectors dedicated to oversight of one specific air carrier. The FAA's traditional approach to ensuring regulatory compliance prior to 2000 was to use its inspector force to conduct spot-checks in the following operational areas:

- Operations inspections focus on such items as pilots' certification and performance, flight crews' training, and in-flight record keeping.

- Maintenance inspections examine an airline's overall maintenance program, including the training of aviation mechanics, the development of maintenance manuals, and procedures for repairing aircraft and their components.

- Avionics inspections focus on electronic components of the aircraft.

- Cabin safety inspections concentrate on cabin procedures, passenger safety, and carry-on baggage (United States of America, GAO, 1999).

After a series of crashes in the early to mid 1990s, President Clinton created the White House Commission on Aviation Safety and Security to investigate new strategies to reduce the number of aviation fatalities. The recommendations of the Commission charged the FAA to work more closely with industry to establish partnership programs, to more effectively use its inspector workforce to oversee industry compliance, and to make better use of emerging technologies to proactively identify safety issues (Gore, 1997). In response to these recommendations, the FAA developed the Air Transportation Oversight System (ATOS) in 1998 to fundamentally change the way it conducted oversight of the nation's largest air carriers. ATOS emphasizes a system safety approach that extends beyond periodically checking airlines for compliance with regulations to using technical and managerial skills to identify, analyze, and control hazards and risks. Under ATOS, inspectors develop surveillance plans for each airline, based on data analysis and risk assessment, and adjust the plans periodically based on inspection results (GAO, 2006). The risk-based approach to oversight inherent in ATOS is dependent upon detailed operational and human factors data to constantly 
evaluate areas of risk and hazard within a carrier. The FAA's limited inspector resources made collecting this volume of information impossible.

To gain access to this valuable safety information, the FAA developed a suite of voluntary self-disclosure programs that offer a regulatory incentive to both air carriers and employees to voluntarily submit incident reports to the agency. The FAA uses the data from voluntary self-disclosures and its close interaction with industry to proactively target its oversight of air carriers, while also identifying systemic areas of safety concern across the national air space system. Importantly, the FAA's traditional inspection processes remain a vital part of the agency's approach to regulatory oversight of air carriers. The combination of robust voluntary self-disclosure programs with the FAA's proactive inspection protocols have been credited for the highest level of safety in the history of the aviation industry (Mouawad \& Drew, 2013). This article will examine two of the most prevalent and widely used voluntary self-disclosure programs: the ASAP and the VDRP.

\section{The ASAP}

Created in 1997, the ASAP is a voluntary disclosure program that allows employees of air carriers to report safety-related events without the FAA or the carrier taking punitive action against the employee based on the information in the report. Unlike other voluntary programs, ASAP involves a partnership between three entities (FAA, Air carrier, and the employee union) that is codified through a Memorandum of Understanding (MOU). A representative from the local FAA CMO, air carrier, and the employee union sit on an ERC to decide if an ASAP report should be accepted into the program and what corrective action, if any, is necessary to remedy the safety concern. ASAP provides the FAA and air carriers valuable safety information it would not otherwise have access to from those on the front lines of aviation. This information is used to proactively identify areas of risk and hazard in a carrier's operation and to develop corrective measures to address these potential safety concerns. Today, there are more than 200 active ASAPs spanning a variety of employee groups including pilots, mechanics, dispatchers, flight crew, and ramp operators. Importantly, air carriers often have more than one ERC - one for pilots, one for mechanics, and so on. A recent account estimates that there are more than 60,000 ASAP reports submitted annually with the number increasing by $20 \%$ annually (Johnson, 2012).

The ERC has several responsibilities including reviewing and analyzing reports submitted under ASAP, determining through consensus if such reports meet the criteria for acceptance into the program (report is made within $24 \mathrm{hr}$ of the incident and does not involve intentional neglect such as alcohol use), 
identifying actual or potential hazards from the information contained in the reports, proposing solutions to safety hazards, and conducting an annual review of the ASAP database to determine whether corrective actions have reduced the reoccurrence of targeted safety events (Kelley, 2010). The ERC will also conduct telephone or face-to-face interviews with employees who reported more serious violations to engage in a deeper examination of the circumstances that led to the incident. This collaborative investigative process gives the FAA inspectors much greater access to internal air carrier operations and procedures than in the past.

A unique feature of the ERC process is that members must come to consensus on both accepting the report into ASAP and the corrective action to resolve the safety hazard. This requires a high degree of collaboration and understanding of each actor's political environment. As one air carrier ASAP manager noted,

We use four union reps and they rotate one month at a time. I've known them all for a long time, several of them were chief check airmen for me in my previous jobs, so they have a trust in me and how I'm going to approach the position, so I would categorize the relationship as excellent. (ASAP Manager Interview, April 26, 2010)

An ASAP manager from another air carrier described the trade-offs between labor and management that can arise in ERC meetings:

The union representative is the guy that fights the company over every one of these disciplinary actions. He is the guy who goes into the boardroom and defends the mechanic. It is hard for him to take his hat off. We come in here and sit down to do an ASAP and the first thing out of his mouth is how many days off did he get? I could care less about that. My goal is to sit down and figure out what the hell is the issue and what could we fix. His goal is to figure out what punishment the mechanic got. This isn't the grievance committee, this is the ERC. The FAA representative will tell him the same thing. He can be argumentative. Don't get me wrong, I was a mechanic. Most of the time, he tries to put a spin on it that the company didn't hold up their end of the bargain. It's always a training issue, it's always a manpower issue. It's not written clearly in the policy. (ASAP Program Manager Interview, April 20, 2010)

When the ERC's proposed corrective action may involve a more systemic problem that requires a change to a company policy or procedure, the ERC has little authority other than recommending to management that a change be made. Some ERCs engage in strategic behavior by waiting to bring an issue to the attention of senior management in each of the organizations (FAA, air 


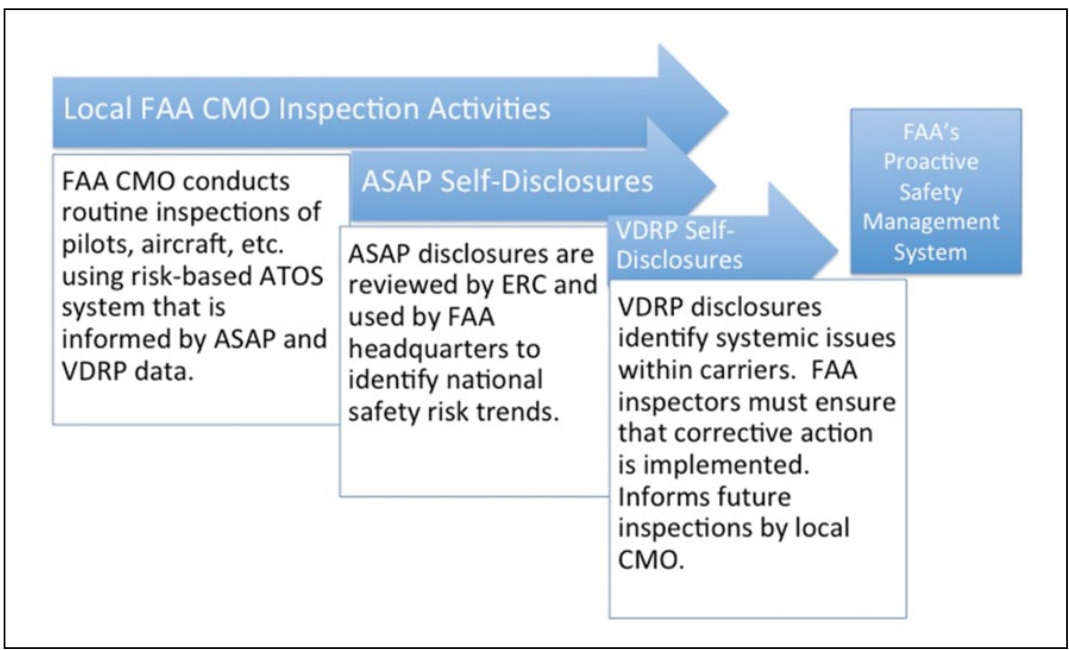

Figure I. Relationship between FAA Inspections and voluntary self-disclosure programs.

Note. FAA = Federal Aviation Administration; $\mathrm{CMO}=$ Certificate Management Offices; ATOS = Air Transportation Oversight System; ASAP = Aviation Safety Action Program; VDRP = Voluntary Disclosure Reporting Program; ERC = Event Review Committee.

carrier, union) until a more severe event takes place (ERC Observation, April 27, 2010).

The data produced through ASAP are used by the air carrier and FAA headquarters to improve safety procedures within the air carrier and to better target increasingly scarce inspector resources to areas of hazard that are both high risk and high probability (Figure 1). Each air carrier is required to have a Continuing Analysis and Surveillance System (CASS) to analyze the trends within the ASAP and VDRP data and to take corrective action as necessary to address those trends. The local FAA CMO also uses the ASAP data trends produced through a carrier's CASS program to identify areas of risk and hazard within the operation. One CMO inspector notes, "Most of the changes resulting from ASAP happen at the local CMO level as opposed to the national level because most problems identified in ASAP are company-specific problems" (FAA Inspector Interview, February 18, 2010). Through its participation in the ERC and its oversight of the air carrier's CASS program, the local FAA office is better able to gain a complete picture of the air carrier's safety culture and is well positioned to assess whether or not the carrier is "gaming" the system by encouraging its employees only to report minor rather than more serious violations through both ASAP and VDRP. 
In addition to using ASAP data at the local level, the FAA wanted to be able to mine this valuable source of data at the national level to look for systemic safety issues across air carriers. However, according to some of our informants, air carriers and employee unions were very concerned about turning identified ASAP reports over to the national FAA office to be shared among competitors. As one air carrier official noted, "The program lives and dies on confidentiality. As soon as that trust is violated, reports will dry up and no one will tell anything" (ASAP Program Manager Interview, April 26, 2010). To ensure the confidentiality of the air carrier and the employee in ASAP reports, the FAA decided to contract with the MITRE Corporation to provide computer servers at each participating air carrier to house their deidentified ASAP and VDRP data. The FAA, in consultation with MITRE, developed Aviation Safety Information Analysis and Sharing (ASIAS), which is a collaborative government and industry initiative on data sharing and analysis to proactively discover safety hazards, leading to timely mitigation and prevention. Once approved by a joint-industry-FAA board, MITRE conducts queries of ASAP and VDRP reports on its servers so that the actual data do not leave the carrier's premises, and the compiled dataset is de-identified by carrier.

To further protect the confidentiality of voluntary self-disclosures, Congress passed and the FAA implemented an order that makes all materials submitted under the ASAP and VDRP, including reports, ERC conversations, a carrier's database of records, trend data of ASAP reports, safety publications, and so on, exempt from the Freedom of Information Act. In addition, ASAP and VDRP materials are not discoverable in legal proceedings against employees or air carriers (Mills, 2010).

\section{The VDRP}

The VDRP is a program that offers certificate holding air carriers reduced regulatory enforcement actions if they voluntarily report systemic problems within their operation and work collaboratively with their local FAA office on designing a comprehensive fix to the problem. For example, an air carrier could self-disclose to the FAA that they were out of compliance with an Airworthiness Directive (AD) that calls for monthly inspections of rudders on 757s. In addition, an air carrier could self-disclose that its pilot training manuals were out of compliance with current FAA regulations. For the FAA to accept a self-disclosure, it must be reported within $24 \mathrm{hr}$ of the air carrier learning of the violation and be the first time the FAA has learned of the violation. Once the violation is self-disclosed to the FAA, the agency and the air carrier work collaboratively to ensure that they have identified the root-cause 
of the violation and any systemic issues that led to the apparent violation. Once the air carrier and the local FAA agree on a corrective action, they work collaboratively on implementing the corrective action within the carrier. The local FAA office also uses the information contained in the self-disclosures to better target its inspections of the air carrier. One of the major differences between other voluntary disclosure programs such as ASAP and VDRP is that the former are employee reporting programs, while the latter is a company or air carrier disclosure program. This difference in the level of disclosure coupled with the need to collaboratively fix the problem identified in the self-disclosure introduces a different decision-making process than is found in employee-level programs such as ASAP. As the Director of Regulatory Compliance for one air carrier noted,

In the self-disclosure process, the company is strategic about what corrective actions it recommends. If we have a known issue with the computer system, we are not going to go out and buy a new computer system just because there is a quirk with it. Could it be fixed? Sure it could be fixed, anything could be fixed. Does it make sense to do it? Hell no. (Director of Regulatory Compliance Interview, April 20, 2010)

VDRP has a poor reputation among many in the public and in Congress due to a high-profile failure of the program that occurred in 2010 involving SWA and the FAA office responsive for overseeing it (United States of America, DOT-IG, 2014). The incident illustrated the complexities of accountability in process-oriented regimes as well as the importance of the design of voluntary reporting programs. As an inspector for the FAA at the SWA CMO, Charalambe Boutris was responsible for inspecting the airframe and systems of the airline's fleet of Boeing 737 jets. In the course of his inspections and as early as 2003, Boutris found that SWA records of AD did not meet the requirements of the law. He informed the SWA maintenance officials and recommended on numerous occasions to his Supervisory Principal Maintenance Inspector (SPMI) Douglas Gawadzinski that they file a letter of investigation (LOI) against SWA. Gawadzinski refused the request by Boutris and instead told him that a safety attributes inspection (SAI) would be conducted to see if the airline was in compliance with federal regulations. SAIs are internal audits conducted by the air carrier and reviewed by the FAA on a routine basis. One year later, when Gawadzinski approved the SAI with Boutris in charge, SWA maintenance officials met with Gawadzinski to have Boutris replaced with a "more friendly supervisor" (United States of America, House of Representatives, Committee on Transportation and Infrastructure, 2008). This once again delayed the SAI, which according to FAA records was 3 years overdue. 
On March 15, 2007, SWA informed Gawadzinski that 47 of their aircraft had over-flown the required fuselage fatigue inspection. On March 19, 2007, SWA's Manager of Regulatory Compliance, a former FAA inspector in the SWA CMO, filed a VDRP claim with the FAA. However, after the VDRP claim was filed, Boutris learned that the affected aircraft continued flying in passenger operations until March 23, 2007, and that six of these aircraft had up to 4-inch cracks in the fuselage, which can lead to a larger breach of the aircraft frame and the rapid depressurization of the cabin (United States of America, House of Representatives, Committee on Transportation and Infrastructure, 2008). On the VDRP application, Gawadzinski falsely confirmed that SWA had ceased operations of the planes after they discovered the crack in the fuselage. In reality, SWA allowed the 47 aircraft to continue in service for up to 30 months after they were due to be inspected. Boutris took this information to the Office of Special Counsel (OSC) and the House Transportation and Infrastructure Committee in August of 2007. The committee ordered the DOT-IG to conduct a review of the incident.

On April 3, 2008, the House Committee on Transportation and Infrastructure, chaired by Representative James L. Oberstar D-MN, conducted a hearing into safety issues at SWA, and possible lapses in FAA oversight. In the testimony following the discovery of the violations, it became clear that Gawadzinski had fallen trap to the "relaxed culture" in the SWA CMO. Specifically, it was determined that Gawadzinski had allowed the noncompliant aircraft to continue to operate because of a close personal relationship with the Manager of Regulatory Affairs at SWA, who also happened to be a former subordinate of Gawadzinski's at the FAA. This relationship led Gawadzinski to trust the intention and general competence of the manager and SWA, even as evidence of lapses accumulated. An investigation of phone records also found that FAA inspectors were in some instances calling SWA maintenance staff to inform them ahead of time of what inspections were coming to file VDRP claims before the FAA inspectors discovered the same violations (United States of America, House of Representatives, Committee on Transportation and Infrastructure, 2008).

In response to the congressional and public concern arising from the SWA incident, the FAA ordered an immediate and nationwide audit of other airlines, to see if they too had any compliance problems with any AD that affected their fleets. Each FAA office that oversees air carriers with aircraft seating 10 or more passengers (so-called "part 121 carriers," as the regulations governing them are found in chapter 121 of the Code of Federal Regulations) was asked to audit $10 \%$ of the ADs applicable to each aircraft type they operate. As a direct result of these "special emphasis" AD audits, problems quickly surfaced with American Airlines' fleet of MD-80s. On March 25 and 26, 2008, FAA inspectors found discrepancies with some of 
American Airlines' MD-80s, and American grounded part of its fleet, canceling a few 100 flights. On April 7, 2008, just 3 days after the congressional hearings arising from the SWA events, FAA inspectors re-inspected 17 of American Airlines' MD-80s and found 16 of them to be out of compliance with AD 2006-15-15. On April 8, faced with the prospect of imminent enforcement action by the FAA, American Airlines chose to ground its entire fleet of MD-80's (more than 350 planes), putting these planes back into service only when the $\mathrm{AD}$ requirements had been completely met, and were to the FAA's satisfaction. From April 8 to 11, American Airlines canceled 3,100 flights, stranding or inconveniencing more than 250,000 passengers (United States of America, Department of Transportation, Report of the Independent Review Team, 2008).

\section{Analysis}

The FAA's voluntary disclosure programs clearly involved multiple accountability frames that structured operations within the network. As a routine matter, they seem to work well, indicating that the shift to a process-oriented regulatory approach has led to increased safety (Mouawad \& Drew, 2013). However, trade-offs between accountability frames within regulatory networks can lead to breakdowns in accountability and eventually crises, as the SWA case illustrates. We will examine the accountability structures both under routine operations and during an extreme incident- the Southwest case.

\section{Routine Operations}

The shift to process-oriented accountability has led to a shift from actors pursuing their own, narrowed accountability frames and instead expanded to include a more collaborative accountability framework to ensure the safety of aviation operations in the United States (Table 3). Collaborative accountability is evident in ASAP as the FAA, air carrier, and unions work collaboratively to identify and fix potential safety hazards that occur during routine operations. Within ASAP, the ERC (and the MOU that codifies the relationship) serves as a collaborative body that helps to minimize other accountability frames that each actor brings to the table. Specifically, while air carriers remain interested in minimizing compliance costs, their participation in ASAP illustrates that the reputation of a safe industry has become a shared norm, and deeply integrated into their shareholder accountability frame. This is further evident in the willingness of air carriers to share de-identified ASAP and VDRP data with other air carriers and FAA headquarters through ASIAS. 
Table 3. Accountability in FAA's Voluntary Disclosure Programs During Routine Operations.

\begin{tabular}{|c|c|c|}
\hline $\begin{array}{l}\text { Accountability } \\
\text { frame }\end{array}$ & $\begin{array}{l}\text { Accountability type } \\
\text { (to whom is account } \\
\text { rendered?) }\end{array}$ & $\begin{array}{c}\text { Application to FAA voluntary self- } \\
\text { disclosure programs during routine } \\
\text { operations }\end{array}$ \\
\hline \multirow[t]{3}{*}{ Democratic } & $\begin{array}{l}\text { Elected } \\
\text { representatives }\end{array}$ & $\begin{array}{l}\text { Funding for inspectors through } \\
\text { appropriations process. Requests for } \\
\text { reports on operation of ASAP and } \\
\text { VDRP during FAA reauthorization } \\
\text { process. }\end{array}$ \\
\hline & $\begin{array}{l}\text { Citizens (and } \\
\text { interests groups) }\end{array}$ & $\begin{array}{l}\text { Limited involvement due to Freedom Of } \\
\text { linfomation Act (FOIA) protections of } \\
\text { ASAP and VDRP disclosures. }\end{array}$ \\
\hline & Legal (Courts) & $\begin{array}{l}\text { FAA retains right to pursue legal and } \\
\text { punitive action against air carriers and } \\
\text { employees for non-disclosed violations. } \\
\text { Limited involvement by outside legal } \\
\text { entities due to non-discoverability of } \\
\text { ASAP and VDRP disclosures in legal } \\
\text { proceedings. }\end{array}$ \\
\hline \multirow[t]{3}{*}{ Market } & Shareholder/owner & $\begin{array}{l}\text { Desire of air carriers to protect } \\
\text { reputation of their company and the } \\
\text { industry for safety while also earning } \\
\text { profits for shareholders by minimizing } \\
\text { cost of corrective actions in ASAP and } \\
\text { VDRP processes. }\end{array}$ \\
\hline & Consumer & $\begin{array}{l}\text { Limited due to inability to make } \\
\text { informed choice on relative safety of } \\
\text { carriers because of ASAP and VDRP } \\
\text { confidentiality. }\end{array}$ \\
\hline & Labor & $\begin{array}{l}\text { Desire of air carrier employee unions } \\
\text { to protect membership from punitive } \\
\text { action and play a participatory role in } \\
\text { enforcing safety standards during ASAP } \\
\text { and VDRP processes. Also, desire } \\
\text { by public sector unions to pursue } \\
\text { additional inspector hiring and protect } \\
\text { existing jobs from downsizing. }\end{array}$ \\
\hline Administrative & $\begin{array}{l}\text { Bureaucratic } \\
\text { (principals, } \\
\text { supervisors, bosses) }\end{array}$ & $\begin{array}{l}\text { Desire by local FAA inspectors to avoid } \\
\text { high-profile incident by following } \\
\text { ASAP and VDRP guidance and by using } \\
\text { data collected through disclosures to } \\
\text { identify weaknesses in air carrier safety } \\
\text { program. }\end{array}$ \\
\hline
\end{tabular}


Table 3. (continued)

\begin{tabular}{|c|c|c|}
\hline $\begin{array}{l}\text { Accountability } \\
\text { frame }\end{array}$ & $\begin{array}{l}\text { Accountability type } \\
\text { (to whom is account } \\
\text { rendered?) }\end{array}$ & $\begin{array}{c}\text { Application to FAA voluntary self- } \\
\text { disclosure programs during routine } \\
\text { operations }\end{array}$ \\
\hline & $\begin{array}{l}\text { Professional } \\
\text { (experts) }\end{array}$ & $\begin{array}{l}\text { Desire by FAA inspectors, air carriers, } \\
\text { and union employees to learn from } \\
\text { ASAP and VDRP reports at the local } \\
\text { level through CASS and ATOS and at } \\
\text { national level through ASIAS. Analysis } \\
\text { is used to inform internal air carrier } \\
\text { audits and FAA inspection activities. }\end{array}$ \\
\hline & $\begin{array}{l}\text { Collaborative (peers, } \\
\text { partners) }\end{array}$ & $\begin{array}{l}\text { Air carriers, local FAA, and unions } \\
\text { working together to improve safety } \\
\text { through data sharing and analysis in } \\
\text { ASAP ERCs. Achieving consensus } \\
\text { for corrective actions through ASAP } \\
\text { ERCs. Air carrier and local FAA } \\
\text { office developing corrective action } \\
\text { for systemic issues identified through } \\
\text { VDRP. Air carriers sharing de-identified } \\
\text { data with FAA through ASIAS to } \\
\text { identify crosscutting safety issues at } \\
\text { national level. }\end{array}$ \\
\hline
\end{tabular}

Note. FAA = Federal Aviation Administration; ASAP = Aviation Safety Action Program; VDRP = Voluntary Disclosure Reporting Program; ERC = Event Review Committee; CASS = Continuing Analysis and Surveillance System; ATOS = Air Transportation Oversight System; ASIAS = Aviation Safety Information Analysis and Sharing.

Focusing on the reputational aspects of shareholder accountability makes collaboration with regulators and employees vital for air carriers who work to protect their reputation by proactively addressing safety hazards in their organizations through the FAA's self-disclosure programs.

Similarly, FAA inspectors lessen their reliance on bureaucratic accountability to foster collective accountability by relying more heavily on reporting programs such as ASAP and VDRP, and targeted inspections informed by the data collected through those programs. In addition, FAA inspectors show deference to collaborative accountability by not using information disclosed through ASAP and VDRP as the basis of punitive actions such as letters of investigation against employees or air carriers. That said, the FAA often does rely on bureaucratic accountability in the implementation of ASAP by following published agency procedures to ensure that each partner in the program is operating in good faith. 
Finally, employee union representatives often rely less on formalized labor accountability (grievance processes, strikes) and more on informally driven labor accountability predicated on a culture of cooperation when participating in ASAP ERCs by agreeing to encourage its membership to report and share the facts of violations to both the FAA and the air carrier. The culture of cooperation builds the capacity for the industry to forge "win-win" expectations between labor (pilots and maintenance workers in particular), shareholders and managers, and federal regulators. However, as our interviewees note, trade-offs between management and labor still exist even in this more collaborative environment. Cooperative labor relations climate have been found to positively influence levels of organizational commitment and union loyalty, as well as productivity and quality of services (Deery \& Iverson, 2005, p. 600).

Importantly, the participation of the FAA, air carrier, and employee union in ASAP and VDRP is rooted in trust among the partners that each will operate in good faith and hold one another accountable only within the construct of the programs. In addition, the structural features of the programs including the de-identification of reporters, the confidentiality of reports, and the exemption from FOIA requests help to build trust through repeated collaboration and demonstrate a generally effective way of garnering a deeper and more goal aligned sense of accountability between shareholders, labor unions, and federal bureaucracies like the FAA. However, the focus on collaborative accountability within ASAP and VDRP has come at the expense of more democratic accountability mechanisms. As Table 3 illustrates, the protection of information contained within ASAP and VDRP disclosures limits the ability of citizens and consumer groups to know which air carriers are safer than others. While the FAA retains the ability to pursue civil penalties against air carriers and enforcement action against pilots, mechanics, and so on, legal accountability for those who may be injured due to a safety hazard identified in a self-disclosure is limited - not because access to the court is barred, but because the information needed to prove violation or other negligence may be protected against disclosure by the programs' terms. Finally, accountability by elected representatives is not usually used during the normal operation of the FAA's voluntary disclosure programs. However, the threat of one of the actors in ASAP or VDRP to involve an elected official in a dispute is a powerful incentive to operate in good faith. While each party has this option, engaging political or legal accountability is risky as it may open multiple parties, including the party filing the grievance letter to Congress, to criticism through hearings or counter-suits. It can also undermine the trust that allows collaborative accountability to work well most of the time. That risk can make participants hesitant to apply it without powerful 
reasons. At the same time, democratic accountability can be an important counterbalance to a regulatory arrangement that has become overly collaborative as illustrated by the case of an abuse of VDRP by SWA.

\section{The Challenges of Accountability in Process-Oriented Regulatory Regimes}

The SWA incident illustrates that even effectively structured process-oriented regulatory regimes can be compromised by an overreliance on one type of accountability. In the SWA case, a close relationship between an FAA supervisory inspector and SWA officials led to an overreliance on a collaborative accountability frame that turned into, essentially, conclusion, and a failure of bureaucratic accountability when the supervisory FAA inspector allowed SWA, whose Manager of Regulatory Compliance was a friend and former employee of the FAA CMO, to submit a disclosure to VDRP even though FAA inspector Boutris had raised concerns about the violations contained in the VDRP disclosure several months earlier. This example underscores the "value neutral" aspect of collaborative accountability, as collaborators may conspire to undertake actions, reinforce actions, or enable actions that work against the public goals of regulation.

Furthermore, following receipt of the disclosure, the FAA CMO allowed the SWA 737s to continue to fly even though they were out of compliance. In this instance, SWA appears to have been focused more on short-term shareholder accountability through cost avoidance than on the possible damage to the company's reputation from a large-scale problem or fine. More importantly, the failure of accountability in relation to SWA led to harsher sanctions when similar problems were discovered at American Airlines, which damaged the reputation of the entire aviation industry.

The case also illustrates one of the primary weaknesses of VDRP compared with ASAP, namely, the lack of labor accountability in the VDRP. The involvement of either the union representing FAA inspector Boutris or the union representing SWA mechanics would likely have prevented the SWA incident by bringing professional and labor accountability to the review of the claims made by Boutris. Instead, the close relationship between supervisory FAA inspector and the SWA Manager of Regulatory Compliance led to an ineffective reliance on a narrow form of collaborative accountability that led to a failure of VDRP to ensure compliance. We find the success of the ASAP premised, at least in part, on the existence of a participatory decisionmaking process involving labor.

The reaction to the SWA case illustrates how elected official accountability can be used to improve the effectiveness of self-disclosure programs. 
When members of Congress learned of the violations at the Southwest CMO and SWA, they called a hearing that put pressure on the FAA to conduct a full safety audit of all major air carriers, thus putting an emphasis on professional and bureaucratic accountability. The SWA case also illustrates that high-profile events can change the dynamics of accountability within regulatory networks by increasing the salience of the issues in play (Gormley, 1986). During routine operations, consumer and legal accountability tend to be minimized by other forms of accountability. However, following a Congressional hearing, consumers became acutely aware of safety issues in both Southwest and American Airlines. Legal accountability played an increased role after the Congressional hearing as both air carriers faced significant civil penalties following the FAA's safety audit, acting as a counterweight to collaborative accountability. Because of the protections on voluntary self-disclosures, the opportunities for consumer and legal accountability in aviation safety networks are often limited to after major incidents.

However, legal accountability was not a significant deterrent prior to the discovery of violations outside of the VDRP process. Specifically, the FAA's process for issuing civil penalties for non-compliant aircraft is calculated using a publicly available fine amount per aircraft operation. As the air carrier continued to fly non-compliant aircraft, the legal (and financial) implications became much more pronounced, leading to a stronger incentive not to truthfully self-disclose the violations. This suggests a possible limitation to the desire of many regulatory agencies to maintain the ability to issue punitive penalties to firms that do not disclose violations.

\section{Conclusion}

Within regulatory networks, there are many accountability frames that interact to ensure compliance with rules and laws. In the case of aviation safety, ensuring that these accountability frameworks are aligned is of utmost importance given the serious risk a breakdown of accountability poses for travelers. The FAA's current approach to regulatory oversight — namely, through the use of voluntary disclosure programs - has resulted in the institutionalization of collaborative accountability mechanisms, while minimizing the dominant accountability frames associated with each actor responsible for ensuring regulatory compliance (in this case, the shareholder accountability of the air carriers and the regulatory bureaucratic accountabilities of FAA regulators). Specifically, the structural elements of the FAA's voluntary programs including the involvement of multiple stakeholders, the threat of fines if air carriers do not submit, and the promise of confidentiality of those who submit reports serve as important balancing mechanisms to keep each actor honest and 
improve the overall effectiveness of the programs. This suggests that as regulators continue to design process-oriented regulatory programs, they must include programmatic elements that allow for collaboration among actors (i.e., the good cop), while still retaining the ability to issue punitive sanctions against those who do not operate in good faith (i.e., bad cop). However, as our analysis of the SWA case illustrates, the threat of a significant fine that builds overtime can lead to a disincentive to self-disclose violations-reducing the overall level of compliance.

Several lessons emerge from the FAA's experience with voluntary selfdisclosure programs that can inform the transition to process-oriented regulatory regimes in other complex industries such as banking, mining, and oil exploration. First as the SWA case illustrates, collaborative accountability can have significant potential limitations. As industry, regulators, and unions become more intertwined, the risk for regulatory capture and noncompliance may increase if regulators and legislators do not balance overarching collaborative accountabilities that pervade in successful process-based regulation with other accountability mechanisms (for instance, bureaucratic accountability through FAA inspections and the value of strong labor accountability in the ASAP). The most important contributing feature to the success of voluntary self-disclosure programs - trust between all partners - can lead to an overreliance on collaborative accountability without the balance of professional or bureaucratic accountability. Relying on professional best practices or established program guidance can reduce the risk of capture or overly close relationships between regulators and firms. Second, labor accountability offers an important counterbalance to shareholder accountability that can work to improve the reputation and performance of an individual firm and entire industry. While aviation may be a unique industry, a high-profile disaster in other industries would also result in increased political attention that could damage the reputation of the individual firm or the industry as a whole through lawsuits (legal accountability) or a loss of profit (shareholder accountability). Involving employees and their unions in the analysis of safety data can help to mitigate potential incidents while also utilizing the expertise of employees (professional accountability).

Our application of the governance network accountability framework to the self-regulation of the airline industry reveals the important role that labor unions play within the complex array of competing, commingling, and conjoining accountability pressures found within this case. We analyzed the overall structure and functionality of process-based regulatory programs like the ASAP and VDRP and by focusing in on a relevant "worst case" scenario in which near tragedy was averted when the VDRP's accountability framework failed. This examination of a narrower case within a system-wide case 
underscores the dynamic nature of the hybridized accountability regimes found within process-oriented regulatory networks like the one studied here. As the case of SWA underscores, accountability trade-offs will surface and recede as contextual pressures ebb and flow over time. By applying the network accountability framework to this and other cases of regulatory failure in similarly high-reliability industries, we may be in a better position to design or redesign process-oriented compliance programs that are effective and consist enough to ensure continuity of regulatory goal attainment.

Our analysis also has several implications for aviation safety regulators in other nations who use or are designing voluntary reporting programs. First, much of the success of voluntary reporting programs depends upon the ability of industry management and labor unions to build trust to work collaboratively to ensure safety. As aviation safety regulators consider how to design programs, it may be necessary to include trust-building forums and mechanisms to build a requisite level of trust for voluntary reporting programs to operate effectively. Second, many nations around the world are seeing new low-cost carriers begin operations. Often, new and smaller carriers lack the institutional capacity and resources to fully implement voluntary programs and are reluctant to participate. Designing incentives and resources to assist these new carriers is vital to avoid the possibility of freeloading across the industry. Finally, the FAA has benefited from collaborative data sharing across the aviation system (i.e., airports, air traffic control, manufacturers, etc.). Encouraging adoption of these programs across all aspects of the aviation system, including private air navigation service providers (ANSPs), increases their robustness and effectiveness.

\section{Declaration of Conflicting Interests}

The author(s) declared no potential conflicts of interest with respect to the research, authorship, and/or publication of this article.

\section{Funding}

The author(s) disclosed receipt of the following financial support for the research, authorship, and/or publication of this article: The authors are thankful for support from the IBM Center for the Business of Government to support the interviews contained within this article.

\section{References}

Angle, H. L., \& Perry, J. L. (1986). Dual commitment and labor-management relationship climates. The Academy of Management Journal, 29, 31-50.

Ayres, I., \& Braithwaite, J. (1992). Responsive regulation: Transcending the deregulation debate. Oxford, UK: Oxford University Press. 
Behn, R. D. (2001). Rethinking democratic accountability. Washington, DC: Brookings Institution Press.

Carpenter, D., \& Krause, G. A. (2015). Transactional authority and bureaucratic politics. Journal of Public Administration Research and Theory, 25, 5-25. doi:10.1093/jopart/muu012

Darnall, N., Potoski, M., \& Prakash, A. (2010). Sponsorship matters: Assessing business participation in government-and industry-sponsored voluntary environmental programs. Journal of Public Administration Research and Theory, 20, 283-307.

Deery, S. J., \& Iverson, R. D. (2005). Labor-management cooperation: Antecedents and impact on organizational performance. Industrial \& Labor Relations Review, $58,588-609$.

Gilad, S. (2010). It runs in the family: Meta-regulation and its siblings. Regulation \& Governance, 4, 485-506.

Gore, A. (1997, February 12). White House Commission on Aviation Safety and Security Final Report. Retrieved from http://www.fas.org/irp/threat/212fin\%7E1. html

Gormley, W. (1986). Regulatory issue networks in a federal system. Polity, 18, 595-620.

Heimer, C. A., \& Gazley, J. L. (2012). Rerforming regulation: Transcending regulatory ritualism in HIV clinics. Law and Society Review, 46, 853-887.

Johnson, B. (2012, July 13). Looking for the big ASAP success story. Aviation Pros. Retrieved from http:/www.aviationpros.com/article/10726469/looking-for-thebig-asap-success-story

Kearney, R. C., \& Hays, S. W. (1994). Labor-management relations and participative decision making: Toward a new paradigm. Public Administration Review, 54, 44-51.

Kelley, K. (2010, June). ASAP 101. Paper presented at the Shared Vision of Aviation Safety Conference, San Diego, CA.

Koliba, C. J., Meek, J., \& Zia, A. (2010). Governance networks in public administration and public policy. Boca Raton, FL: CRC Press.

Koliba, C. J., Mills, R. W., \& Zia, A. (2011). Accountability in governance networks: An assessment of public, private, and nonprofit emergency management practices following Hurricane Katrina. Public Administration Review, 71, 210-220.

Larson, E. (2013). Demand for credit, international financial legitimacy, and vulnerability to crises : Regulatory change and the social origins of Iceland's collapse. Regulation \& Governance. Retrieved from http://doi.org/10.1111/rego.12040

Mashaw, J. L. (2006). Accountability and institutional design: Some thoughts on the grammar of governance. Public Law Working Paper, 116, 115-156.

May, P. J. (2005). Regulation and compliance motivations: Examining different approaches. Public Administration Review, 65, 31-44.

May, P. J. (2007). Regulatory regimes and accountability. Regulation \& Governance, $1,8-26$.

Mills, R. W. (2010). The promise of collaborative voluntary partnerships: Lessons from the federal aviation administration. Washington DC: IBM Center for the Business of Government. 
Mills, R. W., \& Koliba, C. J. (2015). The challenge of accountability in complex regulatory networks: The case of the deepwater horizon oil spill. Regulation \& Governance, 9, 77-91.

Mills, R. W., \& Reiss, D. R. (2013). Secondary learning and the unintended benefits of collaborative mechanisms: The federal aviation administration's voluntary disclosure programs. Regulation \& Governance, 8, 437-454.

Mouawad, J., \& Drew, C. (2013, February 11). Airline industry at its safest since the dawn of the jet age. The New York Times. A1

Parker, C. (2002). The open corporation: Effective self-regulation and democracy. Cambridge, UK: Cambridge University Press.

Prakash, A., \& Potoski, M. (2006). The voluntary environmentalists. Cambridge, UK: Cambridge University Press.

Reiss, D. R. (2011). Account me in: Agencies in quest of accountability. Journal of Law \& Policy, 19, 611-973.

Romzek, B. S., \& Dubnick, M. (1987). Accountability in the public sector: Lessons from the challenger tragedy. Public Administration Review, 47, 227-238.

Rosenbloom, D. H., \& Shafritz, J. M. (1985). Essentials of labor relations. Reston, VA: Reston Publishing.

Scott, C. (2006). Spontaneous accountability. In M. W. Dowdle (Ed.), Public accountability: Designs, dilemmas and experiences (pp. 174-194). Cambridge, UK: Cambridge University Press.

Thornton, D., Gunningham, N., \& Kagan, R. A. (2005). General deterrence and corporate environmental behavior. Law \& Policy, 27, 262-288.

Thornton, D., Kagan, R. A., \& Gunningham, N. (2009). When social norms and pressures are not enough: Environmental performance in the trucking industry. Law \& Society Review, 43, 405-435.

United States of America, Department of Transportation Inspector General. (2014). Further actions are needed to improve FAA's oversight of Voluntary Disclosure Reporting Program (Report ID: AV-2014-036). Washington, DC: U.S. Government Printing Office.

United States of America, Department of Transportation, Report of the Independent Review Team. (2008). Managing risks in civil aviation: A review of the FAA's approach to safety. Washington, DC: U.S. Government Printing Office.

United States of America, Government Accountability Office. (1999). FAA's new inspection system offers promise, but problems need to be addressed. Washington, DC: U.S. Government Printing Office.

United States of America, Government Accountability Office. (GAO) (2006). FAA's Safety Efforts Generally Strong but Face Challenges. Washington, DC: U.S. Government Printing Office.

United States of America, House of Representatives, Committee on Transportation and Infrastructure. (2008, April 1). Critical lapses in FAA safety oversight of airlines: Abuses of regulatory partnership programs. Washington, DC: U.S. Government Printing Office.

van Erp, J. (2011). Naming without shaming: The publication of sanctions in the Dutch financial market. Regulation \& Governance, 5, 287-308. 
Verbruggen, P. (2013). Gorillas in the closet? Public and private actors in the enforcement of transnational private regulation. Regulation \& Governance, 7, 512-532.

Yin, R. (2013). Case study research: Design and methods (5th ed.). Thousand Oaks, CA: Sage.

Zia, A., \& Koliba, C. J. (2011). Climate change governance and accountability: Dilemmas of performance management in complex governance networks. Journal of Comparative Policy Analysis, 13, 479-497.

\section{Author Biographies}

Russell W. Mills is an associate professor in the Department of Political Science at Bowling Green State University. His research interests include governance networks, regulatory politics, and executive-legislative interactions. His work has appeared in a variety of journals including Regulation \& Governance, the Journal of Public Policy, and Public Administration Review.

Christopher J. Koliba is a professor in the Community Development \& Applied Economics Department at the University of Vermont (UVM) and a fellow at the UVM Transportation Research Center and the Gund Institute for Ecological Economics. His research interests include network governance, accountability and performance, natural resource management, and complex adaptive systems. He has published widely in leading public administration and policy studies journals, and is the lead author of the book Governance Networks in Public Administration and Public Policy.

Dorit Rubinstein Reiss is a professor of law at UC Hastings College of the Law. Her research interests include public law; public administration at the local, state, and comparative levels; and, most recently, law and policy related to vaccines. Her work appeared in journals including Law and Policy, NYU's Journal of Legislation and Public Policy, and others. 